\title{
PENGARUH LOKASI DAN FASILITAS TERHADAP KEPUASAN PELANGGAN LIMASAN KAFE KARAWANG
}

\author{
Rido Setiawan ${ }^{1}$ \\ Kosasih $^{2}$ \\ Ajat Sudrajat ${ }^{3}$
}

\author{
Fakultas Ekonomi Universitas Singaperbangsa, Karawang, Indonesia ${ }^{123}$ \\ Email : ridos9033@gmail.com, kosasih@staff.unsika.ac.id, ajat.sudrajat@fe.unsika.ac.id
}

\begin{abstract}
The Effect of Location and Facilities on Limasan Cafe Karawang Customer Satisfaction. The problems of this study are (1) how big is the relationship between location and facilities, (2) how big is the partial influence of location and facilities on customer satisfaction, (3) how big is the simultaneous influence of location and facilities on customer satisfaction.

This research uses a descriptive, verification approach. Samples obtained were 343 respondents who were consumers of Limasan Karawang cafes using incidental sampling techniques, data analysis used in this study was the validity test, reliability test, normality test, path analysis, and hypothesis testing.

Based on the results of the study showed the criteria agreed on the location obtained an average of 1319 and on the facilities obtained an average of 1272. While the Criteria agreed on customer satisfaction obtained an average of 1363. The results showed the location and facilities have a strong relationship, amounting to 0.773 . Location has a direct influence of $39.5 \%$ on customer satisfaction. As for the facility has a direct influence of $4 \%$ on customer satisfaction and both indirect effects on customer satisfaction of $9.7 \%$. So it can be explained that location variables are more dominant in influencing customer satisfaction and Limasan Karawang cafes are advised to pay more attention to facility variables for customer satisfaction convenience.
\end{abstract}

Keywords: Location; Amenities; Customer satisfaction.

\begin{abstract}
Abstrak: Pengaruh Lokasi dan Fasilitas Terhadap Kepuasan Pelanggan Limasan Kafe Karawang. Permasalahan penelitian ini adalah(1) seberapa besar hubungan antara lokasi dan fasilitas,(2) seberapa besarpengaruhparsiallokasidanfasilitasterhadapkepuasanpelanggan,(3)seberapabesarpengaruhsimultan lokasi dan fasilitas terhadap kepuasan pelanggan. Penelitian ini menggunakan pendekatan deskriptif, verifikatif. Sampel yang diperoleh adalah sebanyak 343 responden yang merupakan konsumen dari limasan kafe karawang dengan menggunakan teknik incidental sampling, analisis data yang digunakan pada penelitian ini adalah uji validitas, uji reliabilitas, uji normalitas, analisis jalur, dan uji hipotesis.

Berdasarkan hasil penelitian menunjukkan kriteria setuju pada lokasi memperoleh rata-rata 1319 dan pada fasilitas memperoleh rata-rata sebesar 1272. Sedangkan Kriteria setuju pada kepuasan pelanggan memperoleh rata-rata sebesar 1363. Hasil penelitian menunjukkan lokasi dan fasilitas memiliki hubungan yang kuat, yaitu sebesar 0,773. Lokasi memiliki pengaruh langsung sebesar 39,5\% terhadap kepuasan pelanggan .Adapun fasilitas memiliki pengaruh langsung sebesar 4\% terhadap kepuasan pelanggan dan pengaruh tidak langsung keduanya terhadap kepuasan pelanggan sebesar 9,7\%. Maka dapat dijelaskan bahwa variabel lokasi lebih dominan dalam mempengaruhi kepuasan pelanggan serta Limasan kafe karawang disarankan untuk lebih memperhatikan variabel fasilitas untuk kenyamanan kepuasan pelanggan.
\end{abstract}

Kata kunci: Lokasi; Fasilitas; Kepuasan Pelanggan. 


\section{PENDAHULUAN}

Kabupaten Karawang selain terkenal sebagai sentra bisnis industri dan lapangan kerja, juga terkenal dengan wisata kuliner dengan banyaknya para pelaku bisnis yang membuka usaha kafe. Saat ini, kafe lah yang menjadi sasaran masyarakat untuk hangout apalagi untuk remaja yang sangat ingin populer terhadap kafe baru akan selalu mengejar kafe baru tersebut agar tidak ketinggalan kepopulerannya salahsatunya Limasan Kafe dengan desain yang bervariasi kuno atau Adat Jawa. Apabila pelanggan merasa puas, maka dia akan menunjukkan besarnya kemungkinan untuk kembali membeli produk yang sama juga akan cenderung memberikan referensi yang baik terhadap produk kepada orang lain.

Langkah yang dapat ditempuh untuk menarik kepuasan pelanggan dapat dilakukan dengan cara mengedepankan lokasi. Salah satu strategi perusahaan agar konsumen puas dengan lokasi yaitu pemilihan pada lokasi yang strategis supaya konsumen dapat puas dengan lokasi yang mudah dijangkau.

Salah satu faktor kesuksesan untuk menarik kepuasan pelanggan selain lokasi, diantaranya juga memperhatikan fasilitas. Fasilitas yang ada di Limasan Kafe Karawang memadai sehingga konsumen yang datang ke Limasan Kafe Karawang puas akan fasilitas yang didapatkannya maka konsumen bisa melakukan aktivitas-aktivitas lainnya. Menurut Tjiptono (2011: 38) dalam Faris L. Lumentut dan Indrie D. Palandeng (2014) fasilitas sumber daya fisik yang harus ada sebelum suatu jasa dapat ditawarkan kepada konsumen. Fasilitas dapat pula berupa segala sesuatu yang memudahkan konsumen dalam memperoleh kepuasan.

Sekarang ini Limasan Kafe Karawang sudah dikenal masyarakat Kota Karawang bahkan luar kota dikarenakan perencaanaan ruangan beda tersendiri. Untuk dapatberkembang dan bersaing dalam industri cafe, Limasan Kafe dituntut untuk memiliki keunggulan kompetitif tersendiri dengan menganalisis para pelanggan dalam menentukan kebutuhan dan keinginan serta pada waktu apa saja perusahaan memasarkan produk yang membuat produknya dapat laku keras dipasaran.

Landasan teori, Tjiptono (2008:92) pemilihan letak tempat atau lokasi memerlukan pertimbangan cermat terhadap faktor-faktor seperti: akses, visibilitas, lalu lintas, tempat parkir yang luas, nyaman dan aman, ekspansi, lingkungan, kompetisi dan peraturan pemerintah Menurut Tjiptono (2001: 46-48) indikator fasilitas ada enam, yaitu: pertimbangan/ perencanaan spasial, perencanaan ruang, perlengkapan/perabotan, tata cahaya dan warna, pesan-pesan yang disampaikan secara grafis, unsur pendukung. Menurut Tjiptono (2008: 101) atribut pembentuk kepuasan terdiri dari: kesesuaian harapan, minat berkunjung kembali, kesediaan merekomendasikan.

\section{METODE PENELITIAN}

Jumlah sampel sebanyak 343 dari jumlah populasi sebanyak 5115 responden sebagai pengunjung Limasan Kafe Karawang dengan menggunakan metode Rumus Slovin. Teknik sampling menggunakan teknik accidental sampling dengan penyebaran kuisioner. Adapun teknik analisis dalam penelitian ini menggunakan analisis deskriptif dan veripikatif melalui analisis jalur dan untuk pengujian hipotesis adalah uji statistik secara parsial (uji t) dan uji secara simultan (uji F)

\section{HASIL DAN PEMBAHASAN}

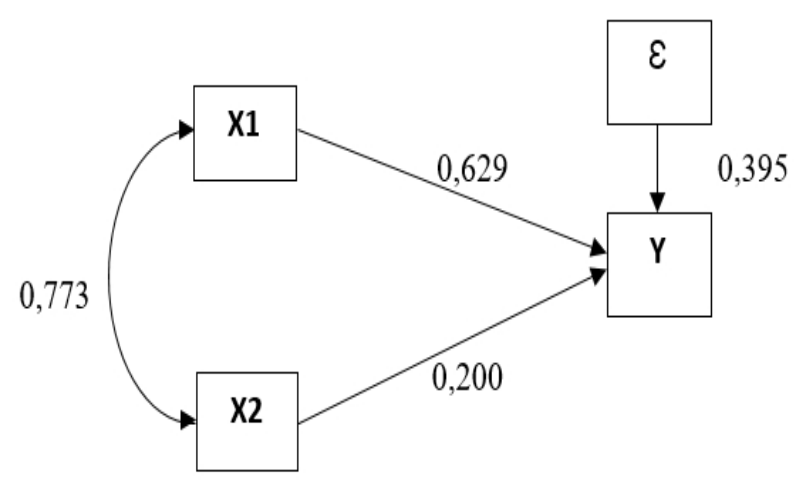

Gambar 1.

Koefisien Jalur Variabel Lokasi (X1) dan Variabel Fasiilitas (X2) tehadap Variabel Kepuasan Pelanggan (Y) 
Nilai koefisen jalur variabel bebas yaitu Lokasi (X1) dan Fasilitas (X2) terhadap variable kepuasan pelanggan $(\mathrm{Y})$ dapat digambarkan pada Gambar 1.

Berdasarkan Gambar 1 menunjukkan bahwa besaran derajat positif asosiatif atau koefisien jalur variabel Lokasi 0,629 lebih tinggi dari pengaruh langsung variabel Fasilitas 0,200. Artinya Lokasi (X1) lebih berpengaruh terhadap Kepuasan Pelanggan (Y) dibandingkan Fasilitas (X2). Adapun persamaan jalurnya adalah sebagai berikut:

$\mathrm{Y}=0,629 \mathrm{X} 1+0,200 \mathrm{X} 2+\varepsilon$

Keterangan:

$\mathrm{X} 1=$ Lokasi

$\mathrm{X} 2=$ Fasilitas

$\mathrm{Y}=$ Kepuasan Pelanggan

$\varepsilon=$ Variabel lain yang tidak diukur dalam penelitian ini, tetapi mempengaruhi $Y$.

Pada Tabel 1 menunjukkan bahwa total pengaruh simultan yang disebabkan lokasi (X1) danfasilitas(X2)terhadap kepuasan pelanggan(Y) yaitu 0,629 atau $62,9 \%$ adapun dari variabel lain diluar model adalah $1-0,629=0,371$ atau $37,1 \%$. Berdasarkan tabel 2, menunjukan bahwa f hitung $=290,841$, dan sig. 0,000. Pengaruh lokasi (X1) dan fasilitas (X2) secara simultan terhadap kepuasan pelanggan (Y) diperlihatkan pada tabel 3 .

Pada Tabel 3, menunjukan bahwa nilai sig. $(0,000)<\alpha(0,05)$ dan $\mathrm{f}$ hitung $(290,841)>\mathrm{f}$ tabel $(3,04)$ maka Ho ditolak. Dengan demikian dapat disimpulkan bahwa lokasi dan fasilitas berpengaruh secara simultan terhadap kepuasan pelanggan. Adapun pembahasan dari metode deskriptif mengenai masing-masing variabel dalam penelitian ini dapat diuraikan sebagai berikut, yakni pada lokasi. Lokasi pada Limasan Kafe Karawang dengan kriteria setuju. Artinya variabel lokasi sudah baik dalam penentuan tempat usaha Pada fasilitas, fasilitas fasilitas pada Limasan Kafe Karawang dengan kriteria setuju. Artinya variabel Fasilitas sudah baik yang disediakan oleh Limasan Kafe Karawang. Pada kepuasan pelanggan

Tabel 1.

Pengaruh Langsung dan Tidak Langsung Lokasi (X1) Fasilitas (X2) terhadap Kepuasan Pelanggan (Y)

\begin{tabular}{cccccc}
\hline Variabel & Koefisien & Pengaruh & \multicolumn{2}{c}{ Pengaruh Tidak Langsung } & Subtotal \\
\cline { 3 - 4 } & Jalur & Langsung & $\mathrm{X} 1$ & $\mathrm{X} 2$ & Pengaruh \\
\cline { 3 - 4 } Lokasi & 0,629 & 0,395 & ------ & 0,097 & 0,492 \\
Fasilitas & 0,200 & 0,04 & 0,097 & ----- & 0,137 \\
Total Pengaruh Simultan & & & & 0,629 \\
Pengaruh Variabel Lain $(£)$ & & & & 0,371 \\
\hline
\end{tabular}

Sumber: Hasil Pengolahan Data Kuesioner 2018, SPSS 22

Tabel 2.

ANOVA $^{\mathrm{a}}$

\begin{tabular}{llrrrrr}
\hline Model & & Sum of Squares & df & Mean Square & F & Sig. \\
\hline 1 & Regression & 963,110 & 2 & 481,555 & 290,841 &, $000^{\mathrm{b}}$ \\
& Residual & 562,948 & 340 & 1,656 & & \\
& Total & 1526,058 & 342 & & & \\
\hline
\end{tabular}
a. Dependent Variable: KEPUASAN PELANGGAN
b. Predictors: (Constant), FASILITAS, LOKASI

Sumber: Hasil Pengolahan Data Kuesioner 2018, SPSS 22 
Tabel 3.

Pengaruh Simultan Lokasi (X1) dan Fasilitas (X2) Terhadap Kepuasan Pelanggan (Y)

\begin{tabular}{cccccc}
\hline Structural & Sig. & A & f hitung & f tabel & Kesimpulan \\
\hline pyx1x2 & 0,000 & 0,05 & 290,841 & 3,04 & Ho ditolak \\
\hline
\end{tabular}

Sumber: Hasil Pengolahan Data Kuesioner 2018, SPSS 22

pada Limasan Kafe Karawang dengan kriteria setuju. Artinya pengunjung merasa puas terhadap pelayanan yang diberikan Limasan Kafe Karawang. Pembahasan verifikatif dalam penelitian ini adalah hubungan lokasi (X1) dan fasilitas (X2) memiliki nilai koefisien korelasi sebesar 0,773 dan mempunyai tingkat hubungan yang kuat dan searah dengan nilai positif. Pengaruh parsial lokasi (X1) dan fasilitas (X2) terhadap kepuasan pelanggan (Y) Pengaruh parsial lokasi (X1) terhadap kepuasan pelanggan (Y) nilainya adalah sebesar 0,395 atau 39,5\% Pengaruh parsial fasilitas (X2) terhadap kepuasan pelanggan (Y) nilainya adalah sebesar 0,04 atau 4\%, karena $0,395(39,5 \%)$ lebih besar dari $0,04(4 \%)$ maka dapat dinyatakan bahwa variabel lokasi (X1) lebih banyak memberikan kontribusi terhadap kepuasan pelanggan $(\mathrm{Y})$

Pengaruh simultan lokasi (X1) dan fasilitas (X2) terhadap kepuasan pelanggan (Y) adalah 0,629 (62,9\%) dengan kriteria uji sig. $(0,000)<a(0,05)$ dan f hitung $(290,841)$ $>$ f tabel $(3,04)$ maka Ho ditolak. Hal ini menunjukkan bahwa lokasi (X1) dan fasilitas (X2) berkontribusi terhadap kepuasan pelanggan (Y) sebesar 53,2\% sedangkan sisanya $100-62,9$ $=37,1 \%$ merupakan kontribusi dari variabel lain $(\varepsilon)$ yang tidak diteliti dalam penelitian ini.

\section{SIMPULAN}

Simpulan dalam penelitian ini adalah variabel lokasi (X1) memiliki nilai indikator yang paling tinggi terletak pada kebersihan yang dimilki Limasan Kafe Karawang. Variabel fasilitas (X2) memiliki nilai indikator yang paling tinggi terletak pada perlengkapan kafe yang dimiliki oleh Limasan Kafe Karawang . Variabel kepuasan pelanggan (Y) ) memiliki nilai indikator yang paling tinggi terletak pada kinerja pelayanan yang diberikan oleh Limasan Kafe Karawang yang dapat menimbulkan loyalitas pelanggan.

\section{REFERENSI}

Ardiawan, P. (2017). Pengaruh Kualitas Pelayanan, Fasilitas, Dan Lokasi Terhadap Kepuasan Konsumen Pada Lapangan Futsal. Simki-Economic Vol. 02 No. 01: 2-9.

Fandy tjiptono. 2008. Service Management. Mewujudkan layanan Prima. Edisi I. Andi. Yogyakarta

Haromain, I., \& Suprihhadi, H. (2016). Pengaruh Kualitas Layanan, Harga, Dan Lokasi Terhadap Kepuasan Pelanggan Di Ahass Z618. Jurnal Ilmu dan Riset Manajemen : Volume 5: 4-17.

Hasibuan, Malayu. 2014. Manajemen: Dasar, Pengertian, dan Masalah. Bumi Aksara, Jakarta.

Hasyim, Lukman Daniel (2016). Pengaruh Lokasi, Pelayanan, Fasilitas Dan Harga Terhadap Kepuasan Konsumen Property "Green Garden Resident" Di Kendal. Jurnal Ekonomi dan Bisnis. Hal 2-16. Universitas Dian Nuswantoro Semarang. Semarang. Iskandarsyah, N. M., \& Utami, S. (2018). Pengaruh Harga, Lokasi, Dan Fasilitas Terhadap Kepuasan Konsumen Pada Perumahan Murah Di. Jurnal Ilmiah Mahasiswa Ekonomi Manajemen Vol. 2, 
No. 1: 129-141.

Kotler, Philip dan Kevin Lane Keller. 2009. Manajemen Pemasaran. Erlangga. Jakarta.

Lumentut, F. L., \& Palandeng, I. D. (2014). Fasilitas, Servicescape, Dan Kualitas Pelayanan, Pengaruhnya Terhadap Kepuasan Konsumen Mcdonald's Manado. Jurnal EMBA Vol.2 No.3: 126-136.

M. Ma'rufAbdullah, SH. MM. 2014. Manajemen dan Evaluasi Kinerja Karyawan. Aswaja Pressindo, Yogyakarta.

Maraji, Wahyu. 2014. Pengaruh Perilaku Konsumen Terhadap Keputusan Pembelian Compact Disc (CD) Di Surabaya. Jurnal Ilmu \& Riset Manajemen Vol. 3 No. 8, Surabaya.

Sugiyono. 2015. Metode Penelitian Kuantitatif, Kualitatif, dan R\&D. Alfabeta, Bandung. 